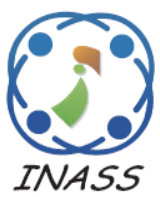

\title{
Modelling and Implementation of Cascaded Multilevel Inverter as Solar PV Based Microinverter Using FPGA
}

\author{
Premkumar Manoharan ${ }^{1 *}$ \\ Sumithira Rameshkumar ${ }^{2}$ \\ ${ }^{I}$ KPR Institute of Engineering and Technology, Coimbatore, India \\ ${ }^{2}$ Government College of Engineering, Salem, India \\ ${ }^{3}$ GMR Institute of Technology, Rajam, India \\ * Corresponding author's Email: mprem.me@gmail.com
}

Sowmya Ravichandran ${ }^{3}$

\begin{abstract}
In the field of power electronics, multilevel inverter plays a vital role for power quality improvement. The high switching frequency is used to obtain quality output waveform with a minimum amount of ripple content. The high voltage is reached by using voltage source inverter with almost zero harmonics without series connected switching devices. If the voltage level increased, the harmonic content of the output voltage waveform decreases in multistage converter. In this present work, single phase cascaded nine level inverter is designed for low powered microinverter and switching angles are produced by Selective Harmonic Elimination (SHE) technique. Each bridge in cascaded inverter will produce the output at different levels and allowing an overall nine level AC output voltage. Now-a-days, the solar photovoltaic is connected with microinverter is an efficient way of increasing the performance so that the proposed inverter derives an input from single PV module since it is module level inverter and it can provide good regulation for leads up to their rated capacity. The prototype is designed for $80 \mathrm{~W}$ rating and the control signals are generated and processed using FPGA controller. The proposed inverter is designed and tested experimentally to verify the theoretical explanations and proposed design delivers high efficiency when compared with the conventional inverter at full load.
\end{abstract}

Keywords: Multilevel inverter, Microinverter, SHE, Solar PV, FPGA controller.

\section{Introduction}

Inverters need to control the output voltage, frequency and also reduced harmonic components in the load current. Most of the variable speed drives, uninterrupted power supplies and many power converting system uses these kind inverters. Designed inverter must provide constant and ripple free voltage to ensure the safety of the different power converting systems. The output voltage of the inverters should close to the ideal AC voltage with low Total Harmonic Distortion (THD) and fast transient response to broad load variations [1].

Module Integrated Converter (MIC) or microinverter are rapidly growing in the field of photovoltaic (PV) system. The MIC will convert the DC of one PV module to the AC and the converter is designed to deliver the maximum output power [2].
The MIC has several advantages such as easy installation, localized maximum power tracking, and robustness when compared to conventional string or central inverters. Many kinds of multilevel inverters are available and merits of such improved output waveform, lower EMI, transformer less high output voltage and compact filter size [3]. Multistage converters gives the output with very less distortion which allows perfect currents, and ripple free voltage waveforms, eliminating most of the undesirable harmonics. The various topologies, control and application of multilevel inverters are observed in [4]. In multistage converter, the bridges works at a very low switching frequency which has the advantage of using low speed semiconductors and results low switching frequency losses. Modular Structured Multilevel Inverter (MSMI) is designed for high power AC power supply application [5] and three 
phase nine level cascaded multilevel inverter is designed to give low harmonics on the output voltage by employing different control strategies [6].

In the proposed research, XILINX web pack software is used to write the coding on the Field Programmable Gate Array (FPGA) controller and it generate gate pulses which is given to the power circuit through the proper isolation and driver circuits. Parallel processing is the most important feature which separates FPGA from processor and make it superior in many fields. FPGA controller requires many clock cycles but it is clocked with higher clock frequency say, $100 \mathrm{MHz}$, the FPGAs offer the speed of processing advantage over the low cost microcontroller. SHE technique is popular and preferable modulation technique for multilevel inverter for low and medium power converters because SHE is operated at low switching frequency in comparison with other PWM techniques, in addition, SHE also improve the quality of the inverter output voltage to obtain low THD [7]. Artificial Neural Network (ANN) is also used to produce switching angle based on the modulation index input by the deriving generalized function [8]. But, the proposed inverter is low rating and to reduce the complexity, ANN is not preferred for the proposed design. SHE technique is selected to generate the desired switching angle for the switching devices and it is developed using Matlab-Simulink and implemented using FPGA to reduce the THD in the output of the 9-level cascaded inverter under steadystate as well asset points tracking with fast transient response [9, 10]. The various FPGA control algorithms for cascaded multilevel inverter is discussed and analysed [11]. Four H-bridge converters are connected in series to form a cascaded multilevel inverter. The output of the 9-level cascaded inverter [12] requires separate DC supply for bridge circuits and conduction angle is controlled to minimize the harmonic distortion in the output voltage. The inverter output voltage is almost sinusoidal, and it has almost 5\% THD with individual H-bridge at fundamental switching frequency.

FPGA based multilevel single phase inverter is designed with different PWM control strategies which reduces the THD in the output voltage at finite rate. Using industrial controller, cascaded nine-level inverter for hybrid-series active power filter is also implemented [13]. The unique multilevel structure of FPGA based cascaded nine level multilevel voltage source inverter is proposed in this research which allows to reach the desired voltages with minimal harmonics with the use of transformer. The transformer leakage energy is handled with the help of decoupling circuit so there is no need of other dissipative circuits, which will reduce the loss and improves the inverter efficiency. Since the inverter is module integrated to derive high output power from the solar PV module, lot of care is given to choose the switching angle at low switching frequency to reduce the switching loss. The proposed inverter is designed with high frequency transformer when compared to the conventional inverter which will reduce the leakage current in the solar PV module because the transformer itself act as decoupling circuit. The proposed model is developed for the rating of $80 \mathrm{~W}$ and tested experimentally.

In the following, Section II introduces various inverter topology and proposed inverter, Section III explains the harmonic elimination theory and switching angle determination, Section IV discusses the simulation results for proposed design and experimental results of the prototype and analysis and section V summarises conclusion and merits.

\section{Inverter topology}

The block diagram for the proposed work is shown in Fig. 1. Cascaded H-bridge multilevel inverter consists of four full bridge inverters, four transformers connected in series on the secondary side of the transformer. Each bridge can create three different voltage levels in AC output voltage waveform and the system allowing an overall nine level AC output voltage.

FPGA controller is used to generate gate pulses and desired switching angle is decided by employing SHE technique. The power circuit consists of four $\mathrm{H}-$ bridges and transformers and it derives the input from 24 cell solar PV module through the DC-DC converter $[14,15]$ for maintaining the constant input voltage to the inverter power circuit. The function of opto coupler is to isolate the control circuit from the

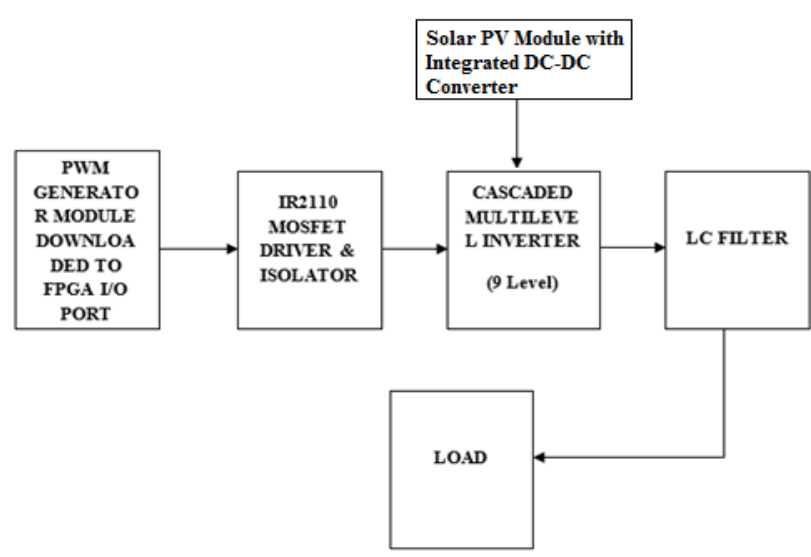

Figure.1 Block diagram of FPGA based 9-level cascaded multilevel inverter 
power circuit. It is essential to provide isolation circuit between power circuit and control circuit or else the high power components may damage the low power PWM circuit components. MOSFET drive circuit is designed to connect the gate directly to a voltage bus with no intervening resistance other than the impedance of the drive circuit switch. Gate driver acts as a high-power buffer stage between the PWM output of the control device and gates of the primary power switching MOSFETs.

\subsection{Power system harmonics}

The output current waveforms are distorted from sine wave at fundamental frequency since the nonlinear loads are represented as current sources. Those loads will draw non-sinusoidal currents from the given power source. Depends on the equipment design, the AC line current is of square wave or a stepped wave. The analysis can be done on the square wave or stepped wave into its equivalent sinusoidal waves of higher frequencies. Then there is a harmonic voltage drop on the power source due to this harmonic currents. This results voltage distortion in power source and the harmonic currents will flows through components and loads.

Harmonic distortion on the waveform is nothing but electrical noise. It will superposition on the signals, which are of multiples of fundamental frequency. Multiplying of power electronic systems results in high harmonic distortion. This results in reduction of power quality and power systems stability. Harmonic problems include variety of electrical disturbances, which may originate in many ways and have different effects on various sensitive loads. Low variations in power source is not noticed in the operation of conventional equipment. As a result, increasing numbers of industrial and commercial facilities are trying to protect by investing in sophisticated and safe equipment to improve power quality. Moreover, the production of nonlinear loads with large power has increased the noise level in voltage and current waveforms, forcing to improve the compensation characteristics required to satisfy additional rigid harmonics standard.

The most commonly used harmonic index is represented in Eq. (1) and (2).

$$
\begin{gathered}
T H D v=\frac{\sqrt{\sum_{h=2}^{\alpha} V h=2}}{V 1} \\
T H D i=\frac{\sqrt{\sum_{h=2}^{\alpha} V h=2}}{I 1}
\end{gathered}
$$

Table 1. IEEE standard for voltage harmonics - (IEEE 519 - voltage distortion limits)

\begin{tabular}{|c|c|c|}
\hline Bus voltage & Individual $\mathbf{V}_{\mathbf{h}}(\boldsymbol{\%})$ & THD $_{\mathbf{v}}(\boldsymbol{\%})$ \\
\hline $\mathrm{V}<69 \mathrm{kV}$ & 3.0 & 5.5 \\
\hline $69 \mathrm{kV}-161 \mathrm{kV}$ & 1.5 & 2.5 \\
\hline $\mathrm{V}=161 \mathrm{kV}$ & 1 & 1.5 \\
\hline
\end{tabular}

Table 2. IEEE standard for current harmonics - general distribution systems $(120 \mathrm{~V}-69 \mathrm{kV})$

\begin{tabular}{|c|c|c|c|c|c|c|}
\hline $\begin{array}{c}\mathbf{I}_{\mathbf{S C}} / \\
\mathbf{I}_{\mathbf{L}}\end{array}$ & $\begin{array}{c}\mathbf{H}< \\
\mathbf{1 1}\end{array}$ & $\begin{array}{c}\mathbf{H}= \\
\mathbf{1 1 - 1 7}\end{array}$ & $\begin{array}{c}\mathbf{H}= \\
\mathbf{1 7 - 2 3}\end{array}$ & $\begin{array}{c}\mathbf{H}= \\
\mathbf{2 3 - 3 5}\end{array}$ & $\begin{array}{c}\mathbf{H}= \\
\mathbf{3 5}\end{array}$ & $\begin{array}{c}\mathbf{T H D}_{\mathbf{i}} \\
(\mathbf{\%})\end{array}$ \\
\hline$<20$ & 4 & 2 & 1.5 & 0.6 & 0.3 & 5.5 \\
\hline $20-50$ & 7.0 & 3.5 & 2.5 & 1.0 & 0.5 & 8 \\
\hline $\begin{array}{c}50- \\
100\end{array}$ & 10 & 4.5 & 4.0 & 1.5 & 0.7 & 12 \\
\hline $\begin{array}{c}100- \\
1000\end{array}$ & 12 & 5.5 & 5.0 & 2.0 & 1.0 & 15 \\
\hline$>1000$ & 15 & 7.0 & 6.0 & 2.5 & 1.4 & 20 \\
\hline
\end{tabular}

The harmonic index is used to measure the deviation of a periodic harmonics from pure sine wave. For pure sine wave at fundamental frequency, the THD is almost zero. Similarly, the measures of individual harmonic distortion for voltage and current at ' $h$ ' order are defined as $\mathrm{V}_{\mathrm{h}} / \mathrm{V}_{1}$ and $\mathrm{I}_{\mathrm{h}} / \mathrm{I}_{1}$ respectively.

Harmonic standards such as IEEE 519-1992 and IEC 1003-3-2 are tabulated in Table 1-2 emphasize placement of limits on harmonic currents produced by the loads for customers and harmonic voltage distortion for the electric utilities. Electrical system has impedance that varies with frequency and a frequency with high system impedance is called resonant frequency. When a VFD or other non-linear device injects a harmonic current at the resonant frequency, the system becomes unstable. Ohms law holds for system resonances. When both current and impedance are high at the same time, voltage goes exceptionally high and causes excessive heating or immediate dielectric failures in capacitors, transformers or other installed devices.

\subsection{Multilevel inverter topology}

Multilevel inverters replace the traditional multipulse converters with/without the need for transformers. The three multilevel inverter topology [16] may be used in reactive power compensation without voltage imbalance problem. Cascaded multilevel inverter with separate DC source will introduce short circuiting when the back-back inverters are not turned on synchronously.

So, to overcome the short circuiting problem, 
Table 3. Comparison of power components requirements

\begin{tabular}{|l|c|c|c|}
\hline $\begin{array}{c}\text { Configura } \\
\text { tion }\end{array}$ & $\begin{array}{c}\text { Diode } \\
\text { Clamped }\end{array}$ & $\begin{array}{c}\text { Flying } \\
\text { Capacitor }\end{array}$ & $\begin{array}{c}\text { Cascad } \\
\text { ed }\end{array}$ \\
\hline $\begin{array}{l}\text { Switching } \\
\text { Device }\end{array}$ & $2(\mathrm{~m}-1)$ & $2(\mathrm{~m}-1)$ & $2(\mathrm{~m}-1)$ \\
\hline Diodes & $2(\mathrm{~m}-1)$ & $2(\mathrm{~m}-1)$ & $2(\mathrm{~m}-1)$ \\
\hline $\begin{array}{l}\text { Clamping } \\
\text { Diodes }\end{array}$ & $(\mathrm{m}-1)(\mathrm{m}-2)$ & 0 & 0 \\
\hline $\begin{array}{l}\text { DC Bus } \\
\text { Capacitors }\end{array}$ & $(\mathrm{m}-1)$ & $(\mathrm{m}-1)$ & $(\mathrm{m}-1)$ \\
\hline $\begin{array}{l}\text { Voltage } \\
\text { Balancing } \\
\text { Capacitors }\end{array}$ & 0 & $(\mathrm{~m}-1)(\mathrm{m}-2) /$ & 0 \\
\hline
\end{tabular}

*m is the level of the output voltage

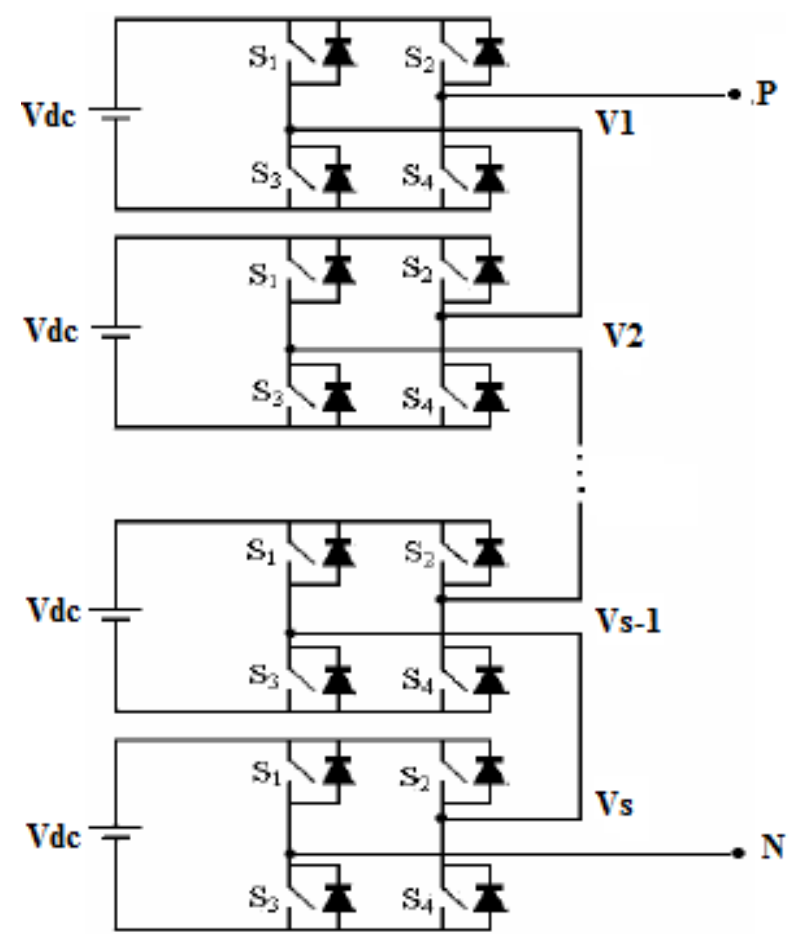

Figure.2 Conventional structure of cascaded multilevel inverter

transformer with one primary and several secondary winding can be used. The following Table 3 describes the number of switching devices and other components for the same voltage level with different configurations.

From the Table 3, the cascaded multilevel inverter requires fewer components than the other two types. The cascaded inverter is having circuit layout flexibility, miniature and modularized circuit and layout packaging and it doesn't require additional clamping diodes and voltage balancing capacitors. The level of the output voltage is adjusted easily by adding or removing the full bridge inverter module. Due to additional feature, the cascaded multilevel inverter is preferred for the proposed design.

\subsubsection{Cascaded multilevel inverter}

The cascaded multilevel inverters are designed with several single phase H-Bridge inverters which are connected in series. By using proper switching device, it is capable of delivering moderate voltage levels and this inverter is formed with three to ten inverters in series to get the required output voltage. Since the each h-bridge inverter is a module with same topology, control and modulation, the cascaded inverters will deliver high modularity degree so that it is easy to replace any faulty module and the faulty module is bypassed without stopping the load.

The power MOSFET is selected to design the $\mathrm{H}$ bridge module and DC source is associated with separate module. The AC output voltage of each level is connected in series to get the desired output voltage. The general structure of cascaded multilevel inverter is shown in Fig. 2.

The proposed inverter consist of four $\mathrm{H}$-bridge fed through single DC supply. The outputs of cascaded h-bridge (CHB) inverter is connected in parallel with the transformer. The secondary side of the transformer is series connected to get the desired voltage. Each module of $\mathrm{CHB}$ inverter has four MOSFETs such that it can produce quasi square wave $(+\mathrm{E}, 0,-\mathrm{E})$ at its output terminal. Where $\mathrm{E}$ is the single DC voltage from solar PV module through DC-DC converter. Q1, Q2, Q3 ...Q16, are the MOSFET switches. T1, T2, T3, T4 are the transformers for cascading the output voltage of the $\mathrm{CHB}$ and delivers the desired output voltage. Fig. 3 illustrates the proposed $\mathrm{CHB}$ multilevel inverter topology with transformer.

The proposed $\mathrm{CHB}$ inverter model in Fig. 3 includes of four transformers and secondary side of the transformer is series connected. Transformer 1, Transformer 2 and Transformer 3 is designed with 1:1 winding ratio and Transformer 4 is designed with $1: 3$ winding ratio which produces the voltage across the load as expressed in Eq. (3). The purpose of transformer is not only to improve the number of output voltage steps, but also provides the isolation between load and source without need of additional DC source. The Eq. (3) provides the total output voltage of the inverter. $\mathrm{V}_{1}, \mathrm{~V}_{2}, \mathrm{~V}_{3}$ and $\mathrm{V}_{4}$ are the terminal voltage of each bridge and the total voltage deliver by the inverter is given by,

$$
\text { Vout }=V_{1}+V_{2}+V_{3}+3 V_{4}
$$

The advantages of the proposed CHB inverter are reduced number of MOSFET devices and simplifies the control complexity as compared with conventional inverter. 


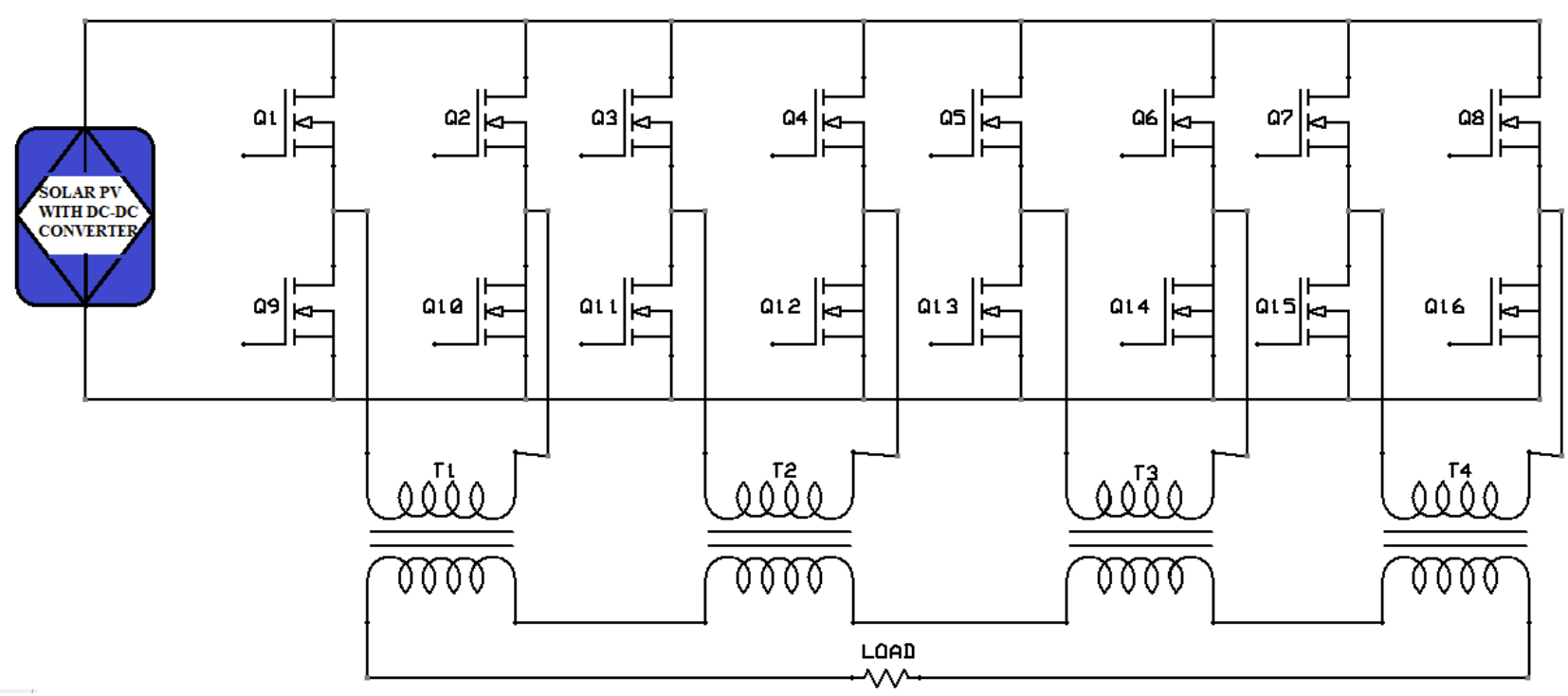

Figure.3 Proposed CHB multilevel inverter with solar PV module

\section{Harmonic elimination theory}

By applying Fourier theory to the output voltage of the multilevel inverter, the expression for the multilevel voltage is obtained. If the DC input voltage to the multilevel inverter is equal, the basic switching frequency control method may be represented as [7],

$$
\begin{gathered}
V(t)=\sum_{n=1,3,5}^{\infty}\left(\frac{4 V_{d c}}{n \pi}\right)\left\{\cos n \theta_{1}+\right. \\
\left.\cos n \theta_{2}+. .+\cos n \theta_{s}\right\} \sin n \omega t
\end{gathered}
$$

where $\theta$ is the switching angle, $V_{\mathrm{dc}}$ is the DC supply voltage derived from the solar PV module of the inverter and $\mathrm{S}$ is the total number of switching angles. The Eq. (4) shows that the output voltage of the inverter doesn't have even order harmonics because the inverter output voltage is odd quarter-wave symmetric. The peak value of the odd order harmonics are represented in terms of device switching angle $\theta_{1}, \theta_{2}$, etc. The harmonics equation of the inverter voltage is derived from the equation 4 which is called as transcendental equation. The $\mathrm{n}^{\text {th }}$ harmonic is eliminated based on harmonic elimination theorywhich is expressed in Eq. (5).

$$
\begin{aligned}
& \cos n \theta_{1}+\cos n \theta_{2}+ \\
& \cos n \theta_{3}+\ldots .+\cos n \theta_{s}=0
\end{aligned}
$$

The harmonic equations for the 9 level CHB inverter is expressed in Eq. (6)-(9),

$$
\begin{aligned}
& \cos \theta_{1}+\cos \theta_{2}+\cos \theta_{3}+\cos \theta_{4}=\frac{4 V d c}{n \pi} \\
& \cos 5 \theta_{1}+\cos 5 \theta_{2}+\cos 5 \theta_{3}+\cos 5 \theta_{4}=0 \\
& \cos 7 \theta_{1}+\cos 7 \theta_{2}+\cos 7 \theta_{3}+\cos 7 \theta_{4}=0
\end{aligned}
$$

$$
\cos 9 \theta_{1}+\cos 9 \theta_{2}+\cos 9 \theta_{3}+\cos 9 \theta_{4}=0
$$

The resolved resultant harmonic elimination equation must be changed to polynomials. Initially, the variables represented in Eq. (10)-(13) must be changed.

$$
\begin{aligned}
& \mathrm{X} 1=\cos \theta_{1} \\
& \mathrm{X} 2=\cos \theta_{2} \\
& \mathrm{X} 3=\cos \theta_{3} \\
& \mathrm{X} 4=\cos \theta_{4}
\end{aligned}
$$

The following trigonometric identities are used to obtain the harmonic polynomial equations.

$$
\begin{aligned}
& \cos 5 \theta=5 \cos \theta-20 \cos 3 \theta+16 \cos 5(\theta) \\
& \cos 7 \theta=-7 \cos \theta-56 \cos 3 \theta-112 \cos 5(\theta)+ \\
& 64 \cos 7 \theta \\
& \cos 9 \theta=9 \cos \theta-120 \cos 3 \theta+432 \cos 5(\theta)- \\
& 576 \cos 7 \theta+256 \cos 9 \theta
\end{aligned}
$$

The Eq. (14)-(16) applied to the transcendental harmonic equation and the polynomial harmonic equations can be expressed in Eq. (17)-(20).

$$
\begin{aligned}
& P_{1}(X 1, X 2, X 3, X 4)=\sum_{n=1}^{4} X n-m=0 \\
& P_{5}(X 1, X 2, X 3, X 4)=\sum_{n=1}^{4} 5 X n-20 X n^{3}- \\
& 16 X n^{5}=0 \\
& P_{7}(X 1, X 2, X 3, X 4)=\sum_{n=1}^{4}-7 X n+56 X n^{3}- \\
& 112 X n^{5}+64 X n^{7}=0 \\
& P_{9}(X 1, X 2, X 3, X 4)=\sum_{n=1}^{4} 9 X n-120 X n^{3}+ \\
& 432 X n^{5}-57664 X n^{7}+256 X n^{9}=0
\end{aligned}
$$


From the above equations, the total harmonic distortion for the inverter output voltage is given in Eq. (21),

$$
\% T H D=\frac{\sqrt{V_{a c}{ }^{2}-V_{a c 1}{ }^{2}}}{V_{a c 1}{ }^{2}}
$$

where $\mathrm{V}_{\mathrm{ac}}$ is rms value of the output voltage and $\mathrm{V}_{\text {ac1 }}$ is rms value of the fundamental voltage.

\subsection{Switching angle analysis}

The property of the inverter output voltage waveform id determined by the modulation technique on the proposed converter. The SHE technique is used to get the 9-level of output voltage. So that the switching angle is selected carefully to avoid/eliminate the odd order harmonics. The SHE technique not only produce the desired switching angle to get output voltage and also minimizes the total harmonic distortion [8]. It also reduces the amount electromagnetic interference and loss due to higher frequency switching.

For the given a desired reference voltage $\mathrm{V}$ from equation 4 , it is necessary to find the switching angles, $\theta_{1}, \theta_{2}, \theta_{3}, \ldots \theta_{\mathrm{s}}$, such a way that, the THD of the output voltage will be minimize. From equation 4 , the Fourier coefficients magnitude with respect to the reference voltage when normalized is expressed in Eq. (22).

$$
\begin{gathered}
V=\left(\frac{4 V_{d c}}{\pi}\right)\left\{\cos \theta_{1}+\cos \theta_{2}+\right. \\
\left.\cos \theta_{3}+\ldots .+\cos n \theta_{s}\right\}
\end{gathered}
$$

The fundamental component amplitude is controlled by the modulation index $(\mathrm{M})$ and is represented in Eq. (23),

$$
M=\frac{V}{V_{d c}}
$$

where $\mathrm{V}$ is the peak value of the output voltage of the inverter.

The Degree of Freedom (DoF) for the CHB inverter which employs SHE technique is $\mathrm{S}$; one of the DoF is selected to find the value of the output voltage presented in Eq. (24) and the remaining DoF is to eliminate harmonic component. By employing SHE, higher order odd harmonic (S-1) will be eliminated.

$$
\cos \theta_{1}+\cos \theta_{2}+. .+\cos n \theta_{16}=\frac{M \pi}{4}
$$

The non-linear transcendental equation which is given in Eq. (4) is solved to determine the approximate value of the switching angle and it must capable to eliminate the harmonics at selected modulation index. It is not possible to find the very accurate solution, because of the non-linearity of the harmonic equation using ordinary mathematical methods. By considering the various factor, Half Equal Phase method is used to produce the switching angles in a best way and it will give the better output waveform, which is in the area between 0 to $\pi / 2$. The switching angle is given by the Eq. (25),

$$
\theta_{i}=i \frac{90^{\circ}}{\frac{m+1}{2}}=i \frac{180^{\circ}}{m+1}
$$

where, $i=1,2, \ldots \ldots \frac{m+1}{2}$ and $m$ is the level of the inverter output voltage. The Eq. (25) is adjusted to extend the switching angle between 0 to $2 \pi$. So that, the possible switching angle combinations may also be obtained.

\section{Results and discussion}

\subsection{Simulation of proposed inverter}

The validation of single phase 9-level cascaded $\mathrm{H}$-bridge microinverter has been done with the help of Matlab/Simulink dynamic simulation software is shown in Fig. 4. The switching angle for the gate signals are achieved by SHE technique which controls sixteen MOSFET switches to get the required output voltage. The gate signal produced by SHE technique is shown in Fig. 5.

In any of the $4 \mathrm{H}$-bridge module, triggering of MOSFET on the same leg should be avoided to avoid short-circuiting the DC voltage which is derived from 24 cell solar PV module. The load output voltage and

FFT analysis for the proposed inverter is shown in Fig. 6 at fundamental frequency of about $50 \mathrm{~Hz}$.

The FFT analysis for the selected 10 cycles is shown in Fig. 7, it can be seen that, there is remarkable change in THD from conventional cascaded H-bridge inverter to the proposed inverter as $28.5 \%$ to $16.11 \%$, because of new inverter topology and switching angle control. The low switching frequency is required for high power application but the proposed inverter is used as microinverter which is designed for less power rating $(<100 \mathrm{~W})$. So, the CHB inverter requires high switching frequency which will high power quality and high range of bandwidth. 


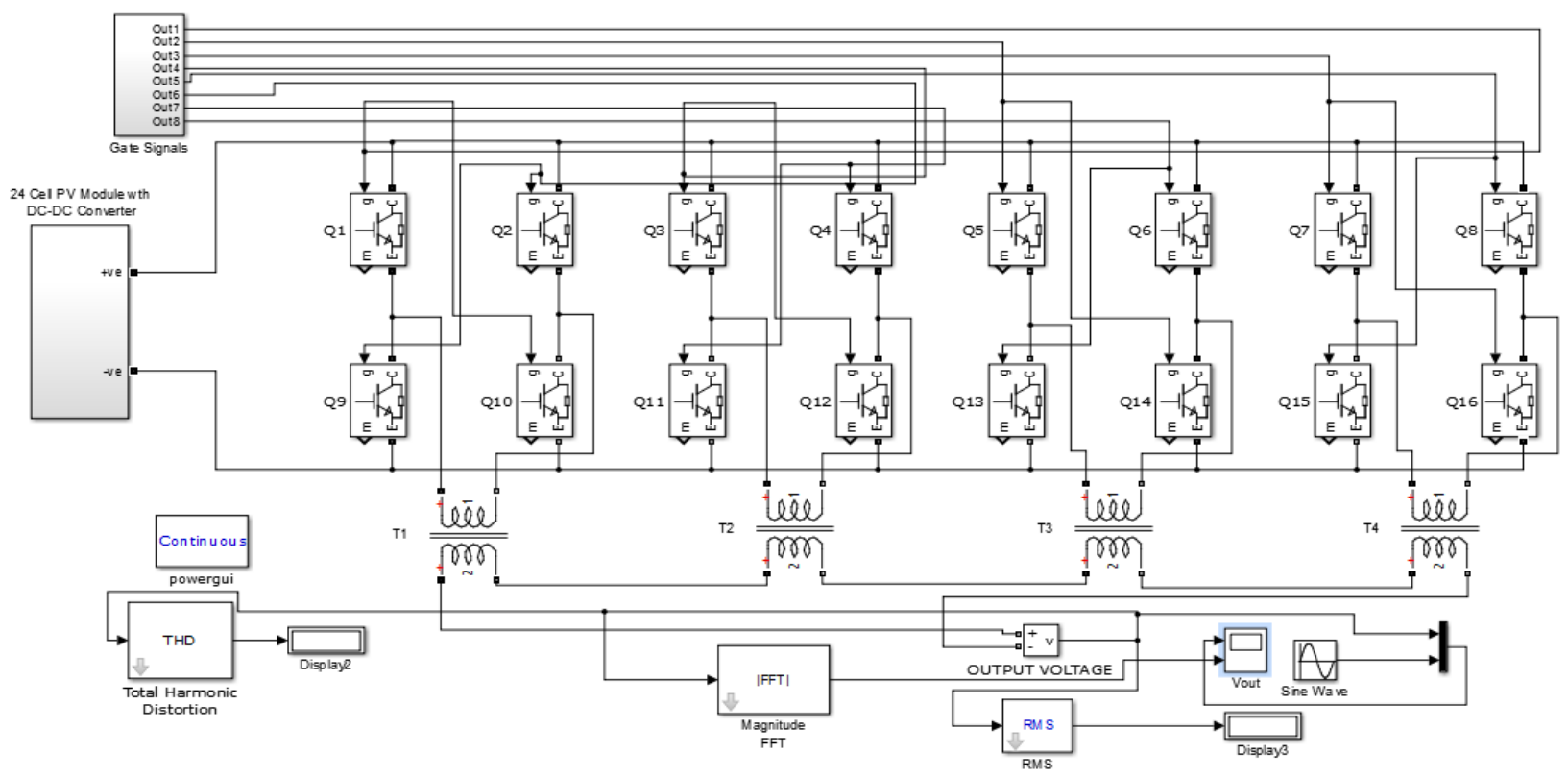

Figure.4 Simulation model of the proposed inverter

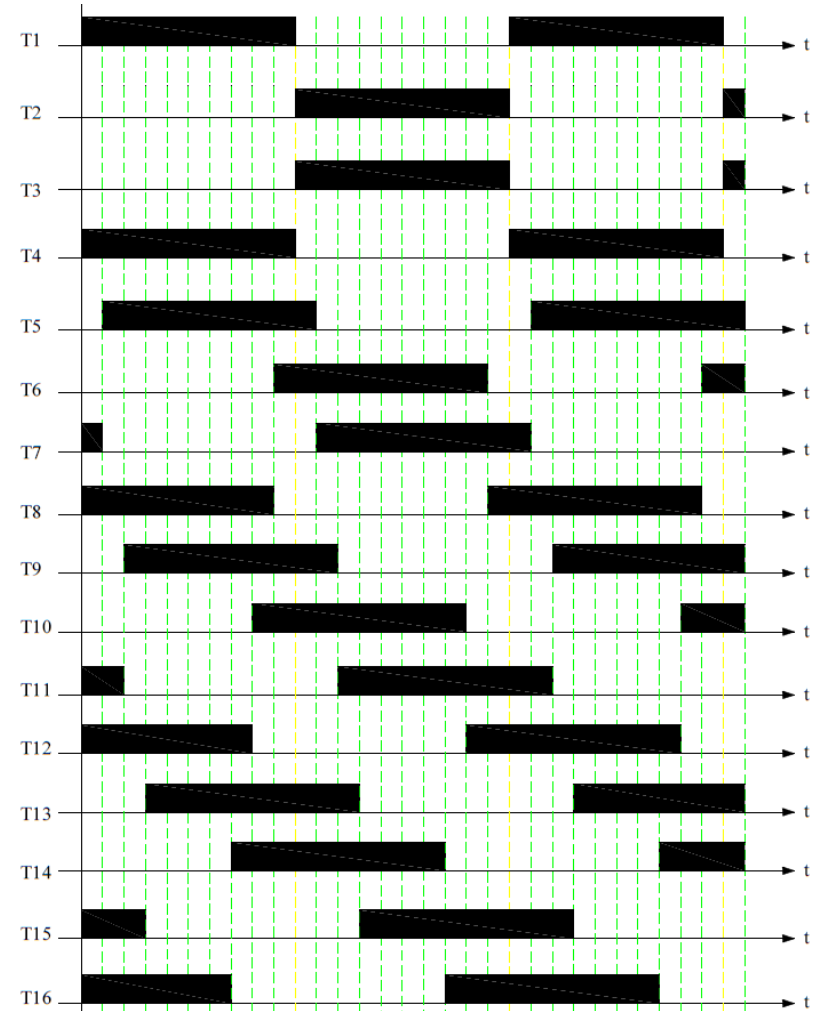

Figure.5 Gating signal for 16 MOSFETs by SHE technique

The THD of the proposed CHB inverter is $16.11 \%$. Similarly, the simulation is done for $3,5,7$, 11 and above up to 15 level using Matlab/Simulink and the results are tabulated in Table 4.

In Table 4, THD for proposed 9-level cascaded $\mathrm{H}$-bridge inverter is highlighted in yellow color which is having less THD than the conventional multilevel inverter and also the number of switching

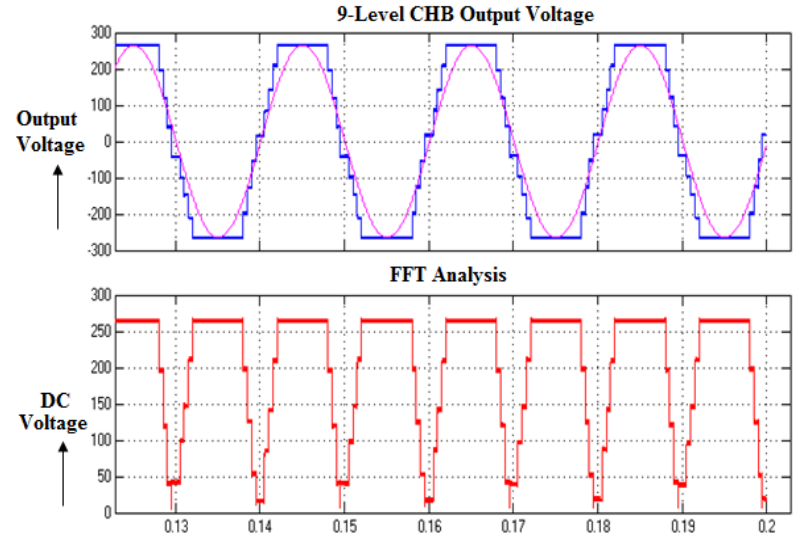

Figure.6 Output voltage waveform and FFT analysis of the inverter at $50 \mathrm{~Hz}$ fundamental frequency

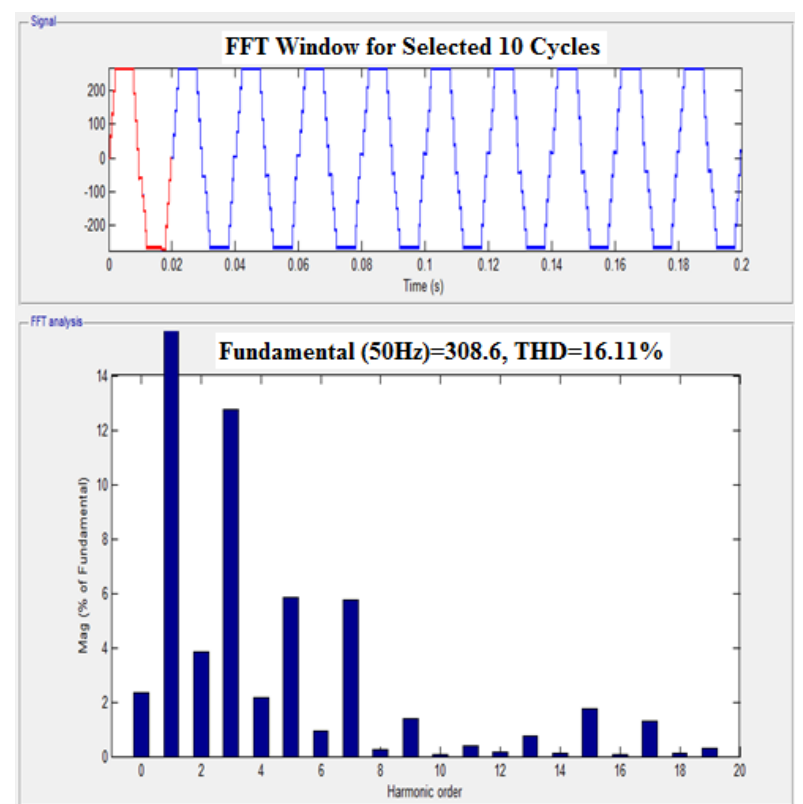

Figure.7 FFT analysis at $50 \mathrm{~Hz}$ fundamental frequency at $\mathrm{THD}=16.11 \%$ for selected 10 cycles 
Table 4. \% THD on different levels of the output voltage @ 14.4V constant input

\begin{tabular}{|c|c|c|c|}
\hline \multirow{2}{*}{ S.No. } & \multirow{2}{*}{$\begin{array}{c}\text { Number } \\
\text { of } \\
\text { Output } \\
\text { Voltage } \\
\text { Levels }\end{array}$} & $\begin{array}{c}\text { \% THD at Fundamental } \\
\text { Frequency of } \\
\mathbf{5 0} \mathbf{~ H z}\end{array}$ \\
\cline { 3 - 4 } & $\begin{array}{c}\text { Conventional } \\
\text { CHB } \\
\text { Multilevel } \\
\text { Inverter }\end{array}$ & $\begin{array}{c}\text { Proposed } \\
\text { CHB } \\
\text { Multilevel } \\
\text { Inverter }\end{array}$ \\
\hline 1 & 3 & 37.70 & 29.45 \\
\hline 2 & 5 & 28.83 & 21.79 \\
\hline 3 & 7 & 28.83 & 19.24 \\
\hline 4 & 9 & 27.41 & 16.11 \\
\hline 5 & 11 & 17.48 & 11.36 \\
\hline 6 & 13 & 15.78 & 9.65 \\
\hline 7 & 15 & 10.74 & 8.71 \\
\hline
\end{tabular}

devices are reduce. So that, the switching loss and conduction loss is reduced than the conventional and offers good performance. The higher output voltage level is having less THD than the conventional but it requires more switching devices which increases the complexity and also the overall loss is proportionally increased.

\subsection{Hardware implementation of CHB 9-level inverter}

The driver circuit of the H-bridge is shown in Fig. 8, it consists of opto coupler for isolating the control circuit and power circuit of the inverter and IR2110 MOSFET driver circuit which is act as a buffer and amplifies the signal from the FPGA controller. The gating signals which is shown in Fig. 9 are generated from the FPGA controller according to SHE technique which is given to the MOSFET in each bridge circuits.

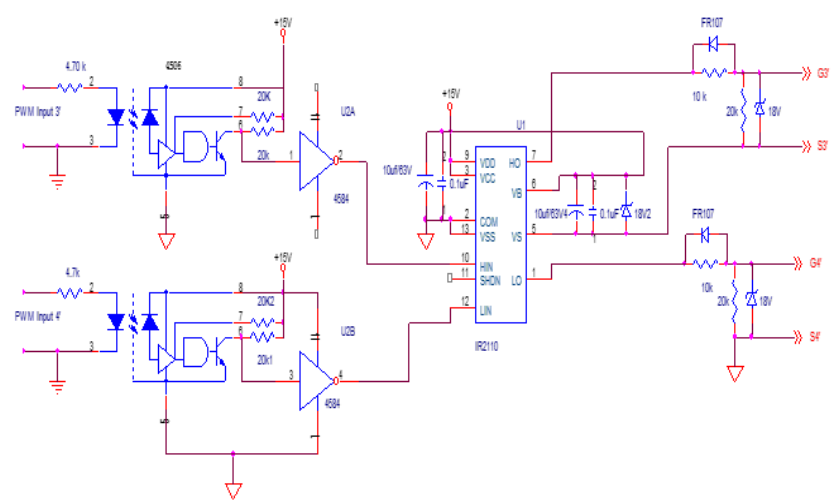

Figure.8 Isolation and driver circuit for MOSFET

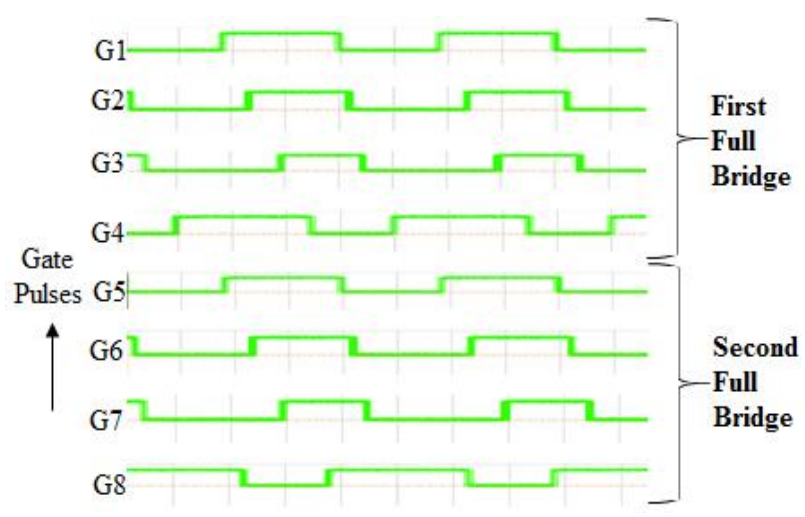

Figure.9 PWM Pulses from FPGA controller

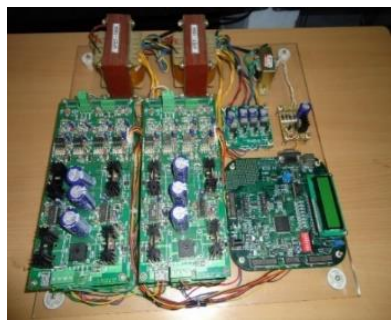

(a)

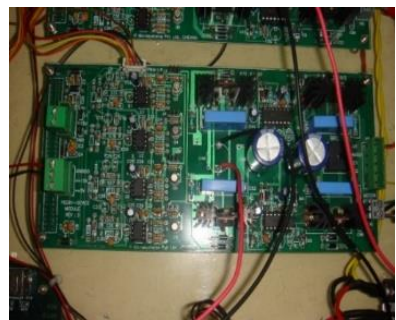

(b)
Figure.10 Hardware model of the proposed inverter: (a) Structure of FPGA controller with the power circuit and (b) Internal power circuit and driver Circuit for $\mathrm{H}$ bridge module

The prototype of a single phase 9-level cascaded multilevel inverter has been designed and fabricated for an output voltage of $230 \mathrm{~V}$ rms voltage. The Fig. 10(a)-(b) shows the hardware structure of the CHB 9-level inverter. The output across the inverter is viewed and analyzed using Digital Storage Oscilloscope (DSO) and power quality analyzer. The obtained hardware result are found that they are closely agree the simulation results.

The Fig. 11 shows the hardware output of a nine level cascaded multilevel inverter. The rms value of the output voltage is $200 \mathrm{~V}$ and the total harmonic distortion is measured by a power quality analyzer. The THD for the proposed inverter output voltage waveform is $9.01 \%$ as shown in Fig. 12, for a modulation index of $95 \%$. Hence, by varying the modulation index for SHE technique, variable voltage and variable frequency output is achieved.

Since the microinverters are particularly designed for low rating, the rating of the solar PV module and device rating are shown in Table 5 and Table 6 respectively. The various loss for the proposed inverter is shown in Table 7. The efficiency of the proposed CHB 9-level inverter is acceptable and it is perfectly suitable for low power solar PV based MIC. The rating of the designed inverter is $80 \mathrm{~W}$ and the model is tested with solar PV module at $1200 \mathrm{~W} / \mathrm{m} 2$ solar irradiation and $37 \mathrm{oC}$ temperature. 


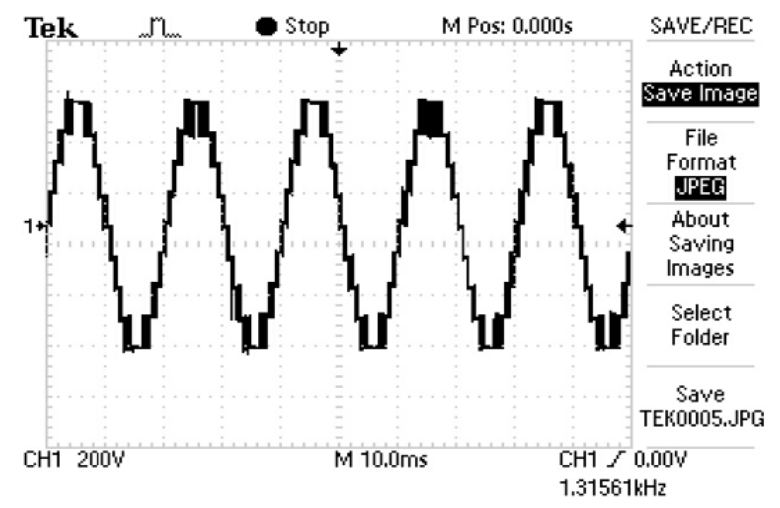

Figure.11 Nine level output voltage waveform at $14.4 \mathrm{~V}$ input from PV module

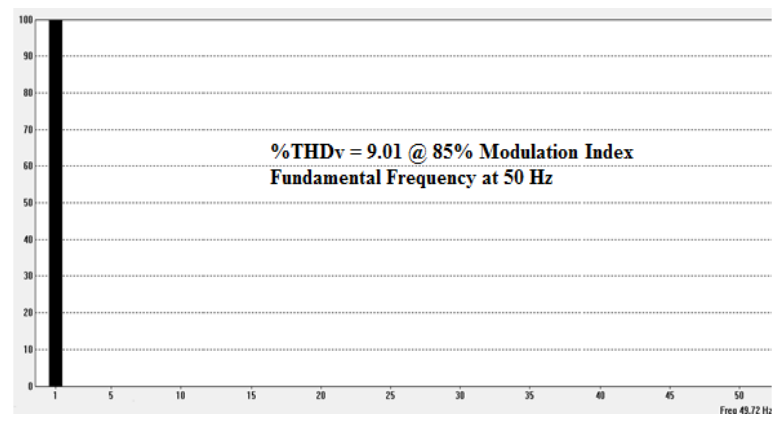

Figure.12 Total harmonic distortion of output waveform $(9.01 \%)$

Table 5. Solar PV module specification Specifications @ $\mathbf{G}=1200 \mathrm{~W} / \mathrm{m}^{2}$ and $\mathbf{T}=37^{\circ} \mathrm{C}$

\begin{tabular}{|c|c|}
\hline Rated Power $\left(\mathrm{P}_{\max }\right)$ & $80 \mathrm{~W}$ \\
\hline Minimum power & $75.6 \mathrm{~W}$ \\
\hline Voltage at $\mathrm{P}_{\max }\left(\mathrm{V}_{\mathrm{mpp}}\right)$ & $12.6 \mathrm{~V}$ \\
\hline Current at $\mathrm{P}_{\max }\left(\mathrm{I}_{\mathrm{mpp}}\right)$ & $6.34 \mathrm{~A}$ \\
\hline Short circuit current $\left(\mathrm{I}_{\mathrm{sc}}\right)$ & $6.78 \mathrm{~A}$ \\
\hline Open circuit voltage $\left(\mathrm{V}_{\mathrm{oc}}\right)$ & $14.4 \mathrm{~V}$ \\
\hline
\end{tabular}

Table 6. CHB inverter specification

\begin{tabular}{|c|c|}
\hline Parameters & Design Value \\
\hline Input voltage range $\mathrm{V}_{\text {in }}$ & $20-60 \mathrm{~V}$ \\
\hline Switching frequency $\mathrm{F}_{\mathrm{s}}$ & $100 \mathrm{kHz}$ \\
\hline Output voltage $\mathrm{V}_{\mathrm{rms}}$ & $230 \mathrm{~V}$ \\
\hline $\begin{array}{c}\text { Rated output power } \\
\mathrm{P}_{\max }\end{array}$ & $80 \mathrm{~W}$ \\
\hline $\begin{array}{c}\text { Based on the rating, SiHF740 MOSFET is } \\
\text { selected for proposed the design }\end{array}$ \\
\hline
\end{tabular}

The proposed inverter is designed with FPGA because the inverter needs high speed operation and controller is used for real time application. So that FPGA can process the signal at fast rate than the microcontroller. The reliability of the inverter with low cost microcontroller [17] is very poor compared to FPGA and without FPGA, two or more inverter gate signals are processed simultaneously according to the rating of the inverter and controller.
Table 7. Inverter Loss with SHE technique

\begin{tabular}{|c|c|c|c|}
\hline $\begin{array}{c}\text { Type of the } \\
\text { loss }\end{array}$ & $\begin{array}{c}\text { Conventio } \\
\text { nal CHB } \\
\text { Inverter } \\
{[\mathbf{4}]}\end{array}$ & $\begin{array}{c}\text { Conventio } \\
\text { nal CHB } \\
\text { Inverter } \\
{[\mathbf{1}]}\end{array}$ & $\begin{array}{c}\text { Propose } \\
\text { d CHB } \\
\text { Inverter }\end{array}$ \\
\hline $\begin{array}{c}\text { Switching } \\
\text { loss }\end{array}$ & 3.752 & 3.154 & 1.754 \\
\hline $\begin{array}{c}\text { Conduction } \\
\text { loss }\end{array}$ & 2.289 & 2.087 & 1.218 \\
\hline $\begin{array}{c}\text { Transformer } \\
\text { losses }\end{array}$ & 0.445 & 0.785 & 1.140 \\
\hline $\begin{array}{c}\text { MOSFET } \\
\text { driver power } \\
\text { consumption }\end{array}$ & 0.148 & 0.146 & 0.129 \\
\hline $\begin{array}{c}\text { Controller } \\
\text { power } \\
\text { consumption }\end{array}$ & 0.136 & 0.128 & 0.114 \\
\hline Total Loss & 6.77 & 6.30 & 4.355 \\
\hline $\begin{array}{c}\text { Efficiency } \\
\text { at the rated } \\
\text { power }\end{array}$ & $\mathbf{9 1 . 5 3 \%}$ & $\mathbf{9 2 . 1 2 \%}$ & $\mathbf{9 4 . 5 5 \%}$ \\
\hline
\end{tabular}

\section{Conclusion}

The 9-level CHB inverter a single supply DC voltage source derived from solar PV module has been modelled and simulated. The proposed inverter produces more accurate results and offers reduced power loss with high output power quality. Based on the results obtained for both the inverter, it proves that SHE will eliminates selected harmonics by chopping out the fundamental component at predetermined switching angles. The proposed inverter almost eliminates $9^{\text {th }}$ order odd harmonics and the remaining higher orders harmonic will be eliminated with filter if desired. Due to the topology and symmetry of switching angle, by default, the higher triple harmonics are eliminated. As per IEEE STD 519 - 1992 harmonic limit, the inverter produces THD within the range of $10 \%$. So, the proposed topology is perfectly suitable for solar PV microinverter rating less than $100 \mathrm{~W}$.

In future, the proposed inverter may be implemented with low cost microcontroller or DSP processor since the cost of FPGA controller is too high which will increase the total cost of the designed system but reliability of the system is good. The proposed inverter is designed as isolated inverter but the design and modulation scheme may be changed to control the common mode ground leakage current between the PV module and the grid if it is installed for grid connected inverter. 


\section{References}

[1] B. Shanthi, and S.P. Natarajan, "FPGA based Fuzzy Logic Control for Single Phase Multilevel Inverter", International Journal of Computer Applications, Vol.9, No.3, pp.10-18, 2010.

[2] M. Premkumar, R. Jeevanantham, and S. Muthuvigneshkumar, "Single Phase Module Integrated Converter Topology for Microgrid Network", International Journal of Innovative Research in Electrical, Electronics, Instrumentation and Control Engineering, Vol.2, No.3, pp.1322-1325, 2014.

[3] G.S. Shehu, T. Yalcinoz, and A.B. Kunya, "Modelling and Simulation of Cascaded $\mathrm{H}$ Bridge Multilevel Single Source Inverter Using PSIM", International Journal of Electrical, Computer, Energetic, Electronic and Communication Engineering, Vol.8, No.5, pp.756-761, 2014.

[4] A. Varschavsky, J. Dixon, M. Rotella, and L. Moran, "Cascaded Nine-Level Inverter for Hybrid-Series Active Power Filter using Industrial Controller", IEEE Transactions on Industrial Electronics, Vol.57, No.8, pp.27612767, 2010.

[5] N.A. Azli and A.H.M. Yatim, "Modular Structured Multilevel Inverter (MSMI) for high power AC Power Supply Application", In: Proc. of IEEE International Symposium on Industrial Electronics, Pusan, South Korea, Vol.2, pp.116121, 2001.

[6] J. Han, T. Tang, B. Pu, Y. Xu, C. Liu, X. Wei, and Y. Gao, "FPGA Based Hybrid Cascade Multilevel Converter", In: Proc. of IEEE International Symposium on Industrial Electronics, Korea, pp.494-498, 2009.

[7] M. G. Fakhry, A. Massoud, and S. Ahmed, "Grid-Connected Cascaded 17-Level H-Bridge Converter with Selective Harmonic Elimination", In: Proc. of $8^{\text {th }}$ IET International Conference on Power Electronics, Machines and Drives, Glasgow, UK, pp.1-5, 2016.

[8] C. Buccella, C. Cecati, M. Gabriella Cimoroni, G. Kulothungan, A. Edpuganti, and A.K. Rathore, "A Selective Harmonic Elimination Method for 5-Level Converters for Distributed Generation", IEEE Journal of Emerging and Selected Topics in Power Electronics, Vol.5, No.2, pp.775-783, 2017.

[9] T. Prathiba and P.Renuga, "Multi Carrier PWM based Multi-Level Inverter for High Power Application", International Journal of
Computer Applications, Vol.1, No.9, pp.67-71, 2010.

[10] B. Urmila and D. Subbarayudu, "Multilevel Inverters: A Comparative Study of Pulse Width Modulation Techniques", International Journal of Scientific \& Engineering Research, Vol.1, No.3, pp.1-5, 2010.

[11] S. Mekhilef and A. Masaoud, "Xilinx FPGA Based Multilevel PWM Single Phase Inverter", In: Proc. of IEEE International Conference on Industrial Technology, Kuala Lumpur, Malaysia, Vol.1, No.2, pp.259-264, 2007.

[12] H.A. Konber, O.I. EL-Hamrawy, and M. EL-Ba, "Implementing a Three Phase Nine-Level Cascaded Multilevel Inverter with Low Harmonics Values", In: Proc. of $14^{\text {th }}$ International Middle East Power Systems Conference, Egypt, pp.983-987, 2010.

[13] Y. Xu, Y. Zou, X. Liu, and Y. He, "A Novel Composite Cascade Multilevel Converter", In: Proc. of $33^{\text {rd }}$ Annual Conference of the IEEE Industrial Electronics Society, Taiwan, pp.1799-1804, 2007.

[14] B.C. Vinayaka and S.N. Prasad, "Modelling and Design of Five Level Cascaded H-Bridge Multilevel Inverter with DC/DC Boost Converter", International Journal of Engineering Research and Applications, Vol.4, No.6, pp.50-55, 2014.

[15] M. Premkumar, N. Dhanasekar, R. Dhivakar, and P. Arunkumar, "Comparison of MPPT Algorithms for PV Systems based DC - DC Converter", Advances in Natural and Applied Sciences, Vol. 17, No.9, pp.212-221, 2016.

[16] M. Malinowski, K. Gopakumar, J. Rodriguez, and M.A. Perez, "A Survey on Cascaded Multilevel Inverters", IEEE Transactions on Industrial Electronics, Vol.57, No.7, pp.21972206, 2010.

[17] T.D. Raj and N.K. Nair, "Implementation of Cascaded H-Bridge Multi Level Inverter", Middle-East Journal of Scientific Research, Vol.24, No.9, pp.2752-2759, 2016. 